\title{
On the Hyers-Ulam Stability of First-Order Impulsive Delay Differential Equations
}

\author{
Akbar Zada, ${ }^{1}$ Shah Faisal, ${ }^{1}$ and Yongjin $\mathrm{Li}^{2}$ \\ ${ }^{1}$ Department of Mathematics, University of Peshawar, Peshawar 25000, Pakistan \\ ${ }^{2}$ Department of Mathematics, Sun Yat-sen University, Guangzhou 510275, China \\ Correspondence should be addressed to Yongjin Li; stslyj@mail.sysu.edu.cn
}

Received 10 December 2015; Revised 12 February 2016; Accepted 23 February 2016

Academic Editor: Janusz Brzdęk

Copyright (c) 2016 Akbar Zada et al. This is an open access article distributed under the Creative Commons Attribution License, which permits unrestricted use, distribution, and reproduction in any medium, provided the original work is properly cited.

\begin{abstract}
This paper proves the Hyers-Ulam stability and the Hyers-Ulam-Rassias stability of nonlinear first-order ordinary differential equation with single constant delay and finite impulses on a compact interval. Our approach uses abstract Gronwall lemma together with integral inequality of Gronwall type for piecewise continuous functions.
\end{abstract}

\section{Introduction}

Ulam, in [1], put a question regarding the stability of functional equation for homomorphism in front of a Mathematical Colloquium. The question was "when an approximate homomorphism from a group $G_{1}$ to a metric group $G_{2}$ can be approximated by an exact homomorphism?"

Within the next two years, Hyers [2] brilliantly gave a partial answer to this question for the case when $G_{1}$ and $G_{2}$ are assumed to be Banach spaces by using direct method. Aoki [3] and Rassias [4] latter extended the partial answer by Hyers. In fact, the most exciting result was by Rassias [4] which weakens the condition for the bound of the norm of Cauchy difference $f(x+y)-f(x)-f(y)$. For further details and discussions, the reader is referred to the book by Jung [5].

As far we know, among the functional equations, Obloza for the first time investigated the stability of differential equations $[6,7]$. After him, Alsina and Ger [8] proved the stability for differential equation $y^{\prime}(x)=y(x)$, which was then generalized for the Banach space valued linear differential equation of first-order $y^{\prime}(x)=\lambda y(x)$, by Takahasi et al. [9]. To study Hyers-Ulam stability of differential equations, different researchers presented their works with different approaches; for example, see [10-25].

Many real world phenomenons are represented by smooth differential equations. However, the situation becomes quite different in the case when a physical phenomenon has sudden changes in its state such as mechanical systems with impact, biological systems like heart beats, blood flows, population dynamics [26, 27], theoretical physics, radio physics, pharmacokinetics, mathematical economy, chemical technology, electric technology, metallurgy, ecology, industrial robotics, biotechnology processes, chemistry [28], engineering [29], control theory, and medicine. Adequate mathematical models of such processes are systems of differential equations with impulses, that is, impulsive differential equations.

An impulsive differential equation is described by three components: a continuous-time differential equation, which governs the state of the system between impulses; an impulse equation, which models an impulsive jump defined by a jump function at the instant an impulse occurs; and a jump criterion, which defines a set of jump events in which the impulse equation is active.

To the best of our knowledge, the first mathematicians who investigated Ulam's type stability of impulsive ordinary differential equations are Wang et al. [30]. They, in 2012, obtained four Ulam's type stability concepts for first-order nonlinear impulsive ordinary differential equation on closed bounded interval with finite impulses. Following their own work, in 2014, they proved the Ulam-Hyers-Rassias stability and generalized Ulam-Hyers-Rassias stability for impulsive evolution equations on a compact interval [31] which then they extended for infinite impulses in the same paper. To study more work on impulsive ODEs we recommend [32-35]. 
However, as far as we know, Ulam's type stability results of impulsive delay ordinary differential equations have not been investigated yet.

In this paper, we obtain Hyers-Ulam stability and HyersUlam-Rassias stability of impulsive delay differential equation of the form

$$
\begin{aligned}
z^{\prime}(t) & =F(t, z(t), z(h(t))), \\
& t \in I^{\prime}=\left[t_{0}, t_{f}\right] \backslash\left\{t_{1}, t_{2}, \ldots, t_{m}\right\}, \\
z(t) & =\alpha(t), \quad t \in\left[t_{0}-\lambda, t_{0}\right], \\
\Delta z\left(t_{k}\right) & =z\left(t_{k}^{+}\right)-z\left(t_{k}^{-}\right)=\Upsilon_{k}\left(z\left(t_{k}^{-}\right)\right), \quad k=1, \ldots, m,
\end{aligned}
$$

where $\lambda>0, t_{f}>t_{0} \geq 0, F:\left[t_{0}, t_{f}\right] \times R^{2} \rightarrow R, \Upsilon_{k}: R \rightarrow R$, and $\alpha:\left[t_{0}-\lambda, t_{0}\right] \rightarrow R$ are continuous. $z\left(t_{k}^{+}\right)=\lim _{\tau \rightarrow 0^{+}} z\left(t_{k}+\right.$ $\tau)$ and $z\left(t_{k}^{-}\right)=\lim _{\tau \rightarrow 0^{+}} z\left(t_{k}-\tau\right)$ are, respectively, the right and left side limits of $z(t)$ at $t_{k}$, where $t_{k}$ satisfy $t_{0}<t_{1}<t_{3}<\cdots<$ $t_{m}<t_{m+1}=t_{f}<+\infty$. Moreover, $h:\left[t_{0}, t_{f}\right] \rightarrow\left[t_{0}-\lambda, t_{f}\right]$ is such that $h(t) \leq t$.

\section{Preliminaries}

In this section we list some important notations, definitions, and lemmas that would be used in our main results.

Throughout this paper, the following spaces appear mostly:

(a) $C[J, R]$ is the Banach space of all continuous real valued functions from $J$ with norm $\|x\|_{C}=\sup \{|x(t)|$ : $t \in J\}$, where $J$ is a compact interval.

(b) $P C\left[t_{0}-\lambda, t_{f}\right]$ denotes the Banach space of all functions $x:\left[t_{0}-\lambda, t_{f}\right] \rightarrow R$ such that $x \in C\left[\left[t_{0}-\right.\right.$ $\left.\left.\lambda, t_{0}\right], R\right] \cap C\left[\left(t_{k}, t_{k+1}\right], R\right], k=0,1,2, \ldots, m$, where $x\left(t_{k}^{+}\right), x\left(t_{k}^{-}\right)$exist and are finite for $k=1,2, \ldots, m$, with norm $\|x\|_{P C}=\sup \left\{|x(t)|: t \in\left[t_{0}-\lambda, t_{f}\right]\right\}$.

(c) $P C^{1}\left[t_{0}, t_{f}\right]=\left\{x \in P C\left[t_{0}-\lambda, t_{f}\right]: x^{\prime} \in P C\left[t_{0}-\lambda, t_{f}\right]\right\}$ is Banach space with norm $\|x\|_{P C^{1}}=\max \left\{\|x\|_{P C}\right.$, $\left.\left\|x^{\prime}\right\|_{P C}\right\}$.

For problem (1), for some $\epsilon>0, \varphi \in P C\left[\left[t_{0}-\lambda, t_{f}\right], R^{+}\right]$, where $\varphi$ is increasing, $\varphi\left(t_{l}\right)=\kappa>0$ for some $t_{l} \in\left[t_{0}-\lambda, t_{f}\right]$, we focus on the following inequalities:

$$
\begin{aligned}
\left|y^{\prime}(t)-F(t, y(t), y(h(t)))\right| & \leq \epsilon, \quad t \in I^{\prime}, \\
\left|\Delta y\left(t_{k}\right)-\Upsilon_{k}\left(y\left(t_{k}^{-}\right)\right)\right| & \leq \epsilon, \quad k=1, \ldots, m, \\
\left|y^{\prime}(t)-F(t, y(t), y(h(t)))\right| & \leq \varphi(t), \quad t \in I^{\prime}, \\
\left|\Delta y\left(t_{k}\right)-\Upsilon_{k}\left(y\left(t_{k}^{-}\right)\right)\right| & \leq \kappa, \quad k=1, \ldots, m .
\end{aligned}
$$

Definition 1. Equation (1) is Hyers-Ulam stable on $\left[t_{0}-\lambda, t_{f}\right]$ if for every $y \in P C\left[t_{0}-\lambda, t_{f}\right] \cap P C^{1}\left[t_{0}, t_{f}\right]$ satisfying (2), there exists a solution $y_{0} \in P C\left[t_{0}-\lambda, t_{f}\right] \cap P C^{1}\left[t_{0}, t_{f}\right]$ of (1) with $\left|y_{0}(t)-y(t)\right| \leq K \epsilon, K>0$, for all $t \in\left[t_{0}-\lambda, t_{f}\right]$.
Definition 2. Equation (1) is Hyers-Ulam-Rassias stable on $\left[t_{0}-\lambda, t_{f}\right]$ with respect to $(\varphi, \kappa)$ if for every $y \in P C\left[t_{0}-\lambda, t_{f}\right] \cap$ $P C^{1}\left[t_{0}, t_{f}\right]$ satisfying (3), there exists a solution $y_{0} \in P C\left[t_{0}-\right.$ $\left.\lambda, t_{f}\right] \cap P C^{1}\left[t_{0}, t_{f}\right]$ of $(1)$ with $\left|y_{0}(t)-y(t)\right|<M \varphi(t), M>0$, for all $t \in\left[t_{0}-\lambda, t_{f}\right]$.

Definition 3. Let $(X ; d)$ be a metric space. An operator $\Lambda$ : $X \rightarrow X$ is a Picard operator if it has a unique fixed point $x^{*} \in X$ such that, for every $x \in X$, the sequence $\left\{\Lambda^{(n)}(x)\right\}_{n \in N}$ converges to $x^{*}$.

We consume what just follow in deriving our main results.

Lemma 4 (Gronwall lemma [36]). If for $t \geq t_{0} \geq 0$ we have

$$
x(t) \leq a(t)+\int_{t_{0}}^{t} b(s) x(s) d s+\sum_{t_{0}<t_{k}<t} \xi_{k} x\left(t_{k}^{-}\right),
$$

where $x, a, b \in P C\left[\left[t_{0}, \infty\right), R^{+}\right], a$ is nondecreasing and $b(t)$, $\xi_{k}>0$. Then for $t \geq t_{0}$ the following inequality works:

$$
x(t) \leq a(t) \prod_{t_{0}<t_{k}<t}\left(1+\xi_{k}\right) \exp \left(\int_{t_{0}}^{t} b(s) d s\right) .
$$

Lemma 5 (abstract Gronwall lemma [37]). Let $(X, d, \leq)$ be an ordered metric space and let $\Lambda: X \rightarrow X$ be an increasing Picard operator with fixed point $x^{*}$. Then for any $x \in X, x \leq$ $\Lambda(x)$ implies $x \leq x^{*}$ and $x \geq \Lambda(x)$ implies $x \geq x^{*}$, where $x^{*}$ is the fixed point of $\Lambda$ in $X$.

Remark 6 (see [30]). A function $y \in P C^{1}\left[t_{0}, t_{f}\right]$ satisfies (2) if and only if there is a function $f \in P C\left[t_{0}-\lambda, t_{f}\right]$ and a sequence $f_{k}$ (which depends on $y$ ) such that $|f(t)| \leq \epsilon$ for all $t \in\left[t_{0}-\lambda, t_{f}\right],\left|f_{k}\right| \leq \epsilon$ for all $k=1,2,3, \ldots, m$, and

$$
\begin{aligned}
y^{\prime}(t) & =F(t, y(t), y(h(t)))+f(t), \quad t \in I^{\prime}, \\
\Delta y\left(t_{k}\right) & =\Upsilon_{k}\left(y\left(t_{k}^{-}\right)\right)+f_{k}, \quad k=1,2,3, \ldots, m .
\end{aligned}
$$

We do similar remark for (3).

Lemma 7. Every $y \in P C^{1}\left[t_{0}, t_{f}\right]$ that satisfies (2) also comes out perfect on the following inequality:

$$
\begin{aligned}
& \mid y(t)-y\left(t_{0}\right)-\sum_{j=1}^{k} \Upsilon\left(y\left(t_{j}^{-}\right)\right) \\
& \quad-\int_{t_{0}}^{t} F(s, y(s), y(h(s))) d s \mid \leq\left(m+t-t_{0}\right) \epsilon,
\end{aligned}
$$

for $t \in\left(t_{k}, t_{k+1}\right] \subset\left[t_{0}, t_{f}\right]$.

Proof. If $y \in P C^{1}\left[t_{0}, t_{f}\right]$ satisfies (2), then by Remark 6 we have

$$
\begin{aligned}
y^{\prime}(t) & =F(t, y(t), y(h(t)))+f(t), \quad t \in I^{\prime}, \\
\Delta y\left(t_{k}\right) & =\Upsilon_{k}\left(y\left(t_{k}^{-}\right)\right)+f_{k}, \quad k=1,2,3, \ldots, m .
\end{aligned}
$$


Then

$$
\begin{aligned}
& y(t)= y\left(t_{0}\right)+\sum_{j=1}^{k} \Upsilon\left(y\left(t_{j}^{-}\right)\right)+\sum_{i=1}^{k} f_{i} \\
&+\int_{t_{0}}^{t} F(s, y(s), y(h(s))) d s+\int_{t_{0}}^{t} f(s) d s, \\
& t \in\left(t_{k}, t_{k+1}\right] .
\end{aligned}
$$

From this the following follows:

$$
\begin{aligned}
& \mid y(t)-y\left(t_{0}\right)-\sum_{j=1}^{k} \Upsilon\left(y\left(t_{j}^{-}\right)\right) \\
& -\int_{t_{0}}^{t} F(s, y(s), y(h(s))) d s\left|\leq \int_{t_{0}}^{t}\right| f(s) \mid d s \\
& +\sum_{i=1}^{k}\left|f_{i}\right| \leq\left(\left(t-t_{0}\right)+k\right) \epsilon \leq\left(t-t_{0}+m\right) \epsilon, \\
& \quad t \in\left(t_{k}, t_{k+1}\right] .
\end{aligned}
$$

We have similar remarks for (3).

\section{Main Results}

Thus far, we were warming up the environment for our main results. Now, we are in position to present our main results.

First we are going to give our result on Hyers-Ulam stability.

Theorem 8. If

(a) $F:\left[t_{0}, t_{f}\right] \times R^{2} \rightarrow R$ is continuous with the Lipschitz condition: $\left|F\left(t, x_{1}, x_{2}\right)-F\left(t, y_{1}, y_{2}\right)\right| \leq \sum_{i=1}^{2} L\left|x_{i}-y_{i}\right|$, $L>0$, for all $t \in\left[t_{0}, t_{f}\right]$ and $x_{i}, y_{i} \in R, i \in\{1,2\}$;

(b) $\Upsilon_{k}: R \rightarrow R$ is such that $\left|\Upsilon_{k}\left(x_{1}\right)-\Upsilon_{k}\left(x_{2}\right)\right| \leq M_{k} \mid x_{1}-$ $x_{2} \mid, M_{k}>0$, for all $k \in\{1,2, \ldots, m\}$ and $x_{1}, x_{2} \in R$, $i \in\{1,2\}$;

(c) $\left(\sum_{i=1}^{m} M_{i}+2 L\left(t_{f}-t_{0}\right)\right)<1$,

then (1) has

(i) a unique solution in $P C\left[t_{0}-\lambda, t_{f}\right] \cap P C^{1}\left[t_{0}, t_{f}\right]$;

(ii) Hyers-Ulam's stability on $\left[t_{0}-\lambda, t_{f}\right]$.

Proof. (i) Define an operator $\Lambda: P C\left[t_{0}-\lambda, t_{f}\right] \rightarrow P C\left[t_{0}-\right.$ $\left.\lambda, t_{f}\right]$ by

$$
(\Lambda z)(t)= \begin{cases}\alpha(t), & t \in\left[t_{0}-\lambda, t_{0}\right], \\ \alpha\left(t_{0}\right)+\int_{t_{0}}^{t} F(r, z(r), z(h(r))) d r, & t \in\left(t_{0}, t_{1}\right], \\ \alpha\left(t_{0}\right)+\Upsilon_{1}\left(z\left(t_{1}^{-}\right)\right)+\int_{t_{0}}^{t} F(r, z(r), z(h(r))) d r, & t \in\left(t_{1}, t_{2}\right], \\ \alpha\left(t_{0}\right)+\sum_{j=1}^{2} \Upsilon_{j}\left(z\left(t_{j}^{-}\right)\right)+\int_{t_{0}}^{t} F(r, z(r), z(h(r))) d r, & t \in\left(t_{2}, t_{3}\right], \\ \vdots & \\ \alpha\left(t_{0}\right)+\sum_{j=1}^{m} \Upsilon_{j}\left(z\left(t_{j}^{-}\right)\right)+\int_{t_{0}}^{t} F(r, z(r), z(h(r))) d r, & t \in\left(t_{m}, t_{m+1}\right] .\end{cases}
$$

We see that for any $z_{1}, z_{2} \in P C\left[t_{0}-\lambda, t_{f}\right]$ and for all $t \epsilon$ $\left[t_{0}-\lambda, t_{0}\right]$ we have $\left|\left(\Lambda z_{1}\right)(t)-\left(\Lambda z_{2}\right)(t)\right|=0$. For $t \in\left[t_{k}, t_{k+1}\right]$ consider

$$
\begin{aligned}
& \left|\left(\Lambda z_{1}\right)(t)-\left(\Lambda z_{2}\right)(t)\right| \leq \sum_{j=1}^{k} \mid \Upsilon_{j}\left(z_{1}\left(t_{j}^{-}\right)\right) \\
& -\Upsilon_{j}\left(z_{2}\left(t_{j}^{-}\right)\right)\left|+\int_{t_{0}}^{t}\right| F\left(r, z_{1}(r), z_{1}(h(r))\right) \\
& \quad-F\left(r, z_{2}(r), z_{2}(h(r))\right) \mid d r \\
& \quad \leq \sum_{j=1}^{k} M_{j}\left|\left(z_{1}\left(t_{j}^{-}\right)\right)-\left(z_{2}\left(t_{j}^{-}\right)\right)\right|+L \int_{t_{0}}^{t} \mid z_{1}(r)
\end{aligned}
$$

$$
\begin{aligned}
& -z_{2}(r)\left|d r+L \int_{t_{0}}^{t}\right| z_{1}(h(r))-z_{2}(h(r)) \mid d r \\
& \leq\left(\sum_{j=1}^{k} M_{j}+2 L\left(t_{f}-t_{0}\right)\right) \sup _{t \in\left[t_{0}-\lambda, t_{f}\right]}\left|z_{1}(t)-z_{2}(t)\right| \\
& \leq\left(\sum_{j=1}^{m} M_{j}+2 L\left(t_{f}-t_{0}\right)\right)\left\|z_{1}-z_{2}\right\| .
\end{aligned}
$$

Following (c), the operator is strictly contractive on $\left(t_{k}, t_{k+1}\right]$, $k=0,1,2, \ldots, m$, and hence a Picard operator on $P C\left[t_{0}-\right.$ $\left.\lambda, t_{f}\right]$. From (11), it follows that the unique fixed point of this operator is in fact the unique solution of (1) in $P C\left[t_{0}-\lambda, t_{f}\right] \cap$ $P C^{1}\left[t_{0}, t_{f}\right]$. 
Next, let $y \in P C\left[t_{0}-\lambda, t_{f}\right] \cap P C^{1}\left[t_{0}, t_{f}\right]$ be a solution to (2). The unique solution $z \in P C\left[t_{0}-\lambda, t_{f}\right] \cap P C^{1}\left[t_{0}, t_{f}\right]$ of the differential equation

$$
\begin{aligned}
z^{\prime}(t) & =F(t, z(t), z(h(t))), \quad t \in I^{\prime} \\
z(t) & =y(t), \quad t \in\left[t_{0}-\lambda, t_{0}\right],
\end{aligned}
$$

$$
\Delta z\left(t_{k}\right)=z\left(t_{k}^{+}\right)-z\left(t_{k}^{-}\right)=\Upsilon_{k}\left(z\left(t_{k}^{-}\right)\right),
$$

is given by

$$
z(t)= \begin{cases}y(t), & t \in\left[t_{0}-\lambda, t_{0}\right], \\ y\left(t_{0}\right)+\int_{t_{0}}^{t} F(r, z(r), z(h(r))) d r, & t \in\left(t_{0}, t_{1}\right], \\ y\left(t_{0}\right)+\Upsilon_{1}\left(z\left(t_{1}^{-}\right)\right)+\int_{t_{0}}^{t} F(r, z(r), z(h(r))) d r, & t \in\left(t_{1}, t_{2}\right], \\ y\left(t_{0}\right)+\sum_{j=1}^{2} \Upsilon_{j}\left(z\left(t_{j}^{-}\right)\right)+\int_{t_{0}}^{t} F(r, z(r), z(h(r))) d r, & t \in\left(t_{2}, t_{3}\right], \\ \vdots & \\ y\left(t_{0}\right)+\sum_{j=1}^{m} \Upsilon_{j}\left(z\left(t_{j}^{-}\right)\right)+\int_{t_{0}}^{t} F(r, z(r), z(h(r))) d r, & t \in\left(t_{m}, t_{m+1}\right] .\end{cases}
$$

We observe that for all $t \in\left[t_{0}-\lambda, t_{0}\right]$ we have $|y(t)-z(t)|=0$. For $t \in\left(t_{k}, t_{k+1}\right]$, using Lemma 7 , we have

$$
\begin{aligned}
& |y(t)-z(t)| \leq \mid y(t)-y\left(t_{0}\right)-\sum_{j=1}^{k} \Upsilon_{j}\left(y\left(t_{j}^{-}\right)\right) \\
& -\int_{t_{0}}^{t} F(s, y(s), y(h(s))) d r \mid \\
& \quad+\int_{t_{0}}^{t} \mid F(r, y(r), y(h(r))) \\
& -F(r, z(r), z(h(r)))\left|d r+\sum_{j=1}^{k}\right| \Upsilon_{j}\left(y\left(t_{j}^{-}\right)\right)
\end{aligned}
$$

$$
\begin{aligned}
& -\Upsilon_{j}\left(z\left(t_{j}^{-}\right)\right)\left|\leq\left(m+t-t_{0}\right) \epsilon+L \int_{t_{0}}^{t}\right| y(r) \\
& -z(r)\left|d r+L \int_{t_{0}}^{t}\right| y(h(r))-z(h(r)) \mid d r \\
& +\sum_{j=1}^{k} M_{j}\left|y\left(t_{j}^{-}\right)-z\left(t_{j}^{-}\right)\right| .
\end{aligned}
$$

Next, we show that the operator $T: P C\left[t_{0}-\lambda, t_{f}\right] \rightarrow P C\left[t_{0}-\right.$ $\left.\lambda, t_{f}\right]$ given below is an increasing Picard operator on $P C\left[t_{0}-\right.$ $\left.\lambda, t_{f}\right]$ :

$$
(\mathrm{Tg})(t)= \begin{cases}0, & t \in\left[t_{0}-\lambda, t_{0}\right], \\ \left(t-t_{0}\right) \epsilon+L \int_{t_{0}}^{t} g(r) d r+L \int_{t_{0}}^{t} g(h(r)) d r, & t \in\left(t_{0}, t_{1}\right], \\ \left(1+t-t_{0}\right) \epsilon+M_{1} g\left(t_{1}^{-}\right)+L \int_{t_{0}}^{t} g(r) d r+L \int_{t_{0}}^{t} g(h(r)) d r, & t \in\left(t_{1}, t_{2}\right], \\ \left(2+t-t_{0}\right) \epsilon+\sum_{j=1}^{2} M_{j} g\left(t_{j}^{-}\right)+L \int_{t_{0}}^{t} g(r) d r+L \int_{t_{0}}^{t} g(h(r)) d r, & t \in\left(t_{2}, t_{3}\right], \\ \vdots & \\ \left(m+t-t_{0}\right) \epsilon+\sum_{j=1}^{m} M_{j} g\left(t_{j}^{-}\right)+L \int_{t_{0}}^{t} g(r) d r+L \int_{t_{0}}^{t} g(h(r)) d r, & t \in\left(t_{m}, t_{m+1}\right] .\end{cases}
$$


For any $g_{1}, g_{2} \in P C\left[t_{0}-\lambda, t_{f}\right],\left|\left(T g_{1}\right)(t)-\left(T g_{2}\right)(t)\right|=0$ for all $t \in\left[t_{0}-\lambda, t_{0}\right]$. For $t \in\left(t_{k}, t_{k+1}\right]$ consider

$$
\begin{aligned}
& \left|\left(T g_{1}\right)(t)-\left(T g_{2}\right)(t)\right| \\
& \leq \sum_{j=1}^{k} M_{j}\left|g_{1}\left(t_{j}^{-}\right)-g_{2}\left(t_{j}^{-}\right)\right| \\
& \quad+L \int_{t_{0}}^{t}\left|g_{1}(r)-g_{2}(r)\right| d r \\
& \quad+L \int_{t_{0}}^{t}\left|g_{1}(h(r))-g_{2}(h(r))\right| d r \\
& \leq \sum_{j=1}^{m} M_{j} \sup _{t \in\left[t_{0}-\lambda, t_{f}\right]}\left|g_{1}(t)-g_{2}(t)\right| \\
& \quad+2 L\left(t_{f}-t_{0}\right) \sup _{t \in\left[t_{0}-\lambda, t_{f}\right]}\left|g_{1}(h(t))-g_{2}(h(t))\right| \\
& \leq\left(\sum_{j=1}^{m} M_{j}+2 L\left(t_{f}-t_{0}\right)\right)\left\|g_{1}-g_{2}\right\| .
\end{aligned}
$$

Since $\left(\sum_{j=1}^{m} M_{j}+2 L\left(t_{f}-t_{0}\right)\right)<1$, the operator is contractive on $P C\left[t_{0}-\lambda, t_{f}\right]$ for $t \in\left(t_{k}, t_{k+1}\right]$, where $k=0,1, \ldots, m$. Applying Banach contraction principle, $T$ is Picard operator with unique fixed $g^{*} \in P C\left[t_{0}-\lambda, t_{f}\right]$; that is,

$$
\begin{aligned}
g^{*}(t)=( & \left(k+t-t_{0}\right) \epsilon+\sum_{j=1}^{k} M_{j} g^{*}\left(t_{j}^{-}\right) \\
& +L \int_{t_{0}}^{t} g^{*}(r) d r+L \int_{t_{0}}^{t} g^{*}(h(r)) d r, \\
& t \in\left(t_{k}, t_{k+1}\right] .
\end{aligned}
$$

$g^{*}$ is increasing, so $g^{*}(h(t)) \leq g^{*}(t)$ and hence we can write

$$
\begin{aligned}
g^{*}(t) \leq & \left(k+t_{f}-t_{0}\right) \epsilon+2 L \int_{t_{0}}^{t} g^{*}(r) d r \\
& +\sum_{j=1}^{k} M_{j} g^{*}\left(t_{j}^{-}\right) .
\end{aligned}
$$

Using Lemma 4, we get

$$
\begin{aligned}
& g^{*}(t) \\
& \quad \leq\left(k+t_{f}-t_{0}\right) \epsilon \prod_{t_{0}<t_{k}<t}\left(1+M_{k}\right) \exp \left(2 L\left(t_{f}-t_{0}\right)\right) .
\end{aligned}
$$

If we set $g=|y-z|$, then from (16), $g(t) \leq(\mathrm{Tg})(t)$ from which, by using abstract Gronwall Lemma, it follows that $g(t) \leq g^{*}$; thus

$$
\begin{aligned}
& |y(t)-z(t)| \\
& \leq\left(m+t_{f}-t_{0}\right) \epsilon \prod_{t_{0}<t_{k}<t}\left(1+M_{k}\right) \exp \left(2 L\left(t_{f}-t_{0}\right)\right) .
\end{aligned}
$$

In the following theorem, we state about the Hyers-UlamRassias stability of (1) on $I=\left[t_{0}-\lambda, t_{f}\right]$. The proof follows the same steps as that of the above theorem. The remarked Lemma 7 for inequality (3) is consumed in the proof.

Theorem 9. If

(a) $F:\left[t_{0}, t_{f}\right] \times R^{2} \rightarrow R$ is continuous with the Lipschitz condition: $\left|F\left(t, x_{1}, x_{2}\right)-F\left(t, y_{1}, y_{2}\right)\right| \leq L \sum_{i=1}^{2}\left|x_{i}-y_{i}\right|$, $L>0$, for all $t \in\left[t_{0}, t_{f}\right]$ and $x_{i}, y_{i} \in R, i \in\{1,2\}$;

(b) $Y_{k}: R \rightarrow R$ is such that $\left|Y_{k}\left(x_{1}\right)-\Upsilon_{k}\left(x_{2}\right)\right| \leq M_{k} \mid x_{1}-$ $x_{2} \mid, M_{k}>0$, for all $k \in\{1,2, \ldots, m\}$ and $x_{1}, x_{2} \in R$, $i \in\{1,2\}$;

(c) $\left(\sum_{i=1}^{m} M_{i}+2 L\left(t_{f}-t_{0}\right)\right)<1$;

(d) $\varphi:\left[t_{0}-\lambda, t_{f}\right] \rightarrow R^{+}$is increasing such that, for some $\rho>0$,

$$
\int_{t_{0}}^{t} \varphi(r) d r \leq \rho \varphi(t)
$$

then (1) has

(i) a unique solution in $P C\left[t_{0}-\lambda, t_{f}\right] \cap P C^{1}\left[t_{0}, t_{f}\right]$;

(ii) Hyers-Ulam-Rassias stability on $\left[t_{0}-\lambda, t_{f}\right]$.

Remark 10. The implications in the above theorem can also be established by assuming that, in (a), "there exists a function $f:\left[t_{0}, t_{f}\right] \rightarrow R^{+}$such that, for all $t \in\left[t_{0}, t_{f}\right]$ and $x_{i}, y_{i} \in R$, $i \in\{1,2\}$, we have $\left|F\left(t, x_{1}, x_{2}\right)-F\left(t, y_{1}, y_{2}\right)\right| \leq \sum_{i=1}^{2} f(t) \mid x_{i}-$ $y_{i} \mid . "$

Remark 11. We notice that our results in this paper have also some practical meanings in the following sense. Consider a phenomenon which has sudden changes in state at some finite instants of time which follows model (1). In general, we can not expect any exact solution to (1). So what is required is to find a function that approximates (1); our results guarantee that there is an exact solution $y(t)$ of (1) close to that approximate solution. In fact, our results are important when finding an exact solution is quit difficult and hence are important in approximation theory and so forth.

\section{Competing Interests}

The authors declare that they have no competing interests.

\section{Acknowledgments}

This work was supported by the National Natural Science Foundation of China (11571378).

\section{References}

[1] S. M. Ulam, A Collection of the Mathematical Problems, Interscience Publishers, New York, NY, USA, 1960.

[2] D. H. Hyers, "On the stability of the linear functional equation," Proceedings of the National Academy of Sciences of the United States of America, vol. 27, pp. 222-224, 1941. 
[3] T. Aoki, "On the stability of the linear transformation in Banach spaces," Journal of the Mathematical Society of Japan, vol. 2, pp. 64-66, 1950.

[4] T. M. Rassias, "On the stability of the linear mapping in Banach spaces," Proceedings of the American Mathematical Society, vol. 72, no. 2, pp. 297-300, 1978.

[5] S.-M. Jung, Hyers-Ulam-Rassias Stability of Functional Equations in Nonlinear Analysis, vol. 48 of Springer Optimization and Its Applications, Springer, New York, NY, USA, 2011.

[6] M. Obloza, "Hyers stability of the linear differential equation," Rocznik Naukowo-Dydaktyczny. Prace Matematyczne, vol. 13, pp. 259-270, 1993.

[7] M. Obloza, "Connections between Hyers and Lyapunov stability of the ordinary differential equations," Rocznik NaukowoDydaktyczny. Prace Matematyczne, vol. 14, pp. 141-146, 1997.

[8] C. Alsina and R. Ger, "On some inequalities and stability results related to the exponential function," Journal of Inequalities and Applications, vol. 2, no. 4, pp. 373-380, 1998.

[9] S.-E. Takahasi, T. Miura, and S. Miyajima, "On the Hyers-Ulam stability of the Banach space-valued differential equation $y=$ $\lambda y$," Bulletin of the Korean Mathematical Society, vol. 39, no. 2, pp. 309-315, 2002.

[10] J. Brzdek and N. Eghbali, "On approximate solutions of some delayed fractional differential equations," Applied Mathematics Letters, vol. 54, pp. 31-35, 2016.

[11] S.-M. Jung, "Hyers-Ulam stability of linear differential equations of first order III," Journal of Mathematical Analysis and Applications, vol. 311, no. 1, pp. 139-146, 2005.

[12] J. Huang, S.-M. Jung, and Y. Li, "On Hyers-Ulam stability of nonlinear differential equations," Bulletin of the Korean Mathematical Society, vol. 52, no. 2, pp. 685-697, 2015.

[13] J. Huang and Y. Li, "Hyers-Ulam stability of linear functional differential equations," Journal of Mathematical Analysis and Applications, vol. 426, no. 2, pp. 1192-1200, 2015.

[14] J. Huang and Y. Li, "Hyers-Ulam stability of delay differential equations of first order," Mathematische Nachrichten, vol. 289, no. 1, pp. 60-66, 2016.

[15] J. Huang, Q. H. Alqifiary, and Y. Li, "Superstability of differential equations with boundary conditions," Electronic Journal of Differential Equations, vol. 2014, pp. 1-8, 2014.

[16] Y. Li and Y. Shen, "Hyers-Ulam stability of nonhomogeneous linear differential equations of second order," International Journal of Mathematics and Mathematical Sciences, vol. 2009, Article ID 576852, 7 pages, 2009.

[17] Y. Li and Y. Shen, "Hyers-Ulam stability of linear differential equations of second order," Applied Mathematics Letters, vol. 23, no. 3, pp. 306-309, 2010.

[18] T. Li, A. Zada, and S. Faisal, "Hyers-Ulam stability of nth order linear differential equations," The Journal of Nonlinear Science and Applications, vol. 9, no. 5, pp. 2070-2075, 2016.

[19] T. Miura, S. Miyajima, and S.-E. Takahasi, "A characterization of Hyers-Ulam stability of first order linear differential operators," Journal of Mathematical Analysis and Applications, vol. 286, no. 1, pp. 136-146, 2003.

[20] D. Popa and I. Raşa, "Hyers-Ulam stability of the linear differential operator with nonconstant coefficients," Applied Mathematics and Computation, vol. 219, no. 4, pp. 1562-1568, 2012.

[21] H. Rezaei, S.-M. Jung, and T. M. Rassias, "Laplace transform and Hyers-Ulam stability of linear differential equations," Journal of Mathematical Analysis and Applications, vol. 403, no. 1, pp. 244251, 2013.
[22] C. Wang and T.-Z. Xu, "Hyers-Ulam stability of fractional linear differential equations involving Caputo fractional derivatives," Applications of Mathematics, vol. 60, no. 4, pp. 383-393, 2015.

[23] B. Xu and J. Brzdęk, "Hyers-Ulam stability of a system of first order linear recurrences with constant coefficients," Discrete Dynamics in Nature and Society, vol. 2015, Article ID 269356, 5 pages, 2015.

[24] B. Xu, J. Brzdek, and W. Zhang, "Fixed-point results and the Hyers-Ulam stability of linear equations of higher orders," Pacific Journal of Mathematics, vol. 273, no. 2, pp. 483-498, 2015.

[25] A. Zada, O. Shah, and R. Shah, "Hyers-Ulam stability of nonautonomous systems in terms of bounded-ness of Cauchy problems," Applied Mathematics and Computation, vol. 271, pp. 512-518, 2015.

[26] D. D. Bainov and A. B. Dishliev, "Population dynamics control in regard to minimizing the time necessary for the regeneration of a biomass taken away from the population," Comptes Rendus de l'Academie Bulgare des Sciences, vol. 42, no. 12, pp. 29-32, 1989.

[27] S. I. Nenov, "Impulsive controllability and optimization problems in population dynamics," Nonlinear Analysis: Theory, Methods \& Applications, vol. 36, no. 7, pp. 881-890, 1999.

[28] D. D. Bainov and P. S. Simenov, Systems with Impulse Effect Stability Theory and Applications, Ellis Horwood Limited, Chichester, UK, 1989.

[29] A. B. Dishliev and D. D. Bainov, "Dependence upon initial conditions and parameter of solutions of impulsive differential equations with variable structure," International Journal of Theoretical Physics, vol. 29, no. 6, pp. 655-675, 1990.

[30] J. Wang, M. Feckan, and Y. Zhou, "Ulam's type stability of impulsive ordinary differential equations," Journal of Mathematical Analysis and Applications, vol. 395, no. 1, pp. 258-264, 2012.

[31] J. Wang, M. Feckan, and Y. Zhou, "On the stability of first order impulsive evolution equations," Opuscula Mathematica, vol. 34, no. 3, pp. 639-657, 2014.

[32] C. Parthasarathy, "Existence and Hyers-Ulam stability of nonlinear impulsive differential equations with nonlocal conditions," Electronic Journal of Mathematical Analysis and Applications, vol. 4, no. 1, pp. 106-115, 2016.

[33] M. Gowrisankar, P. Mohankumar, and A. Vinodkumar, "Stability results of random impulsive semilinear differential equations," Acta Mathematica Scientia, vol. 34, no. 4, pp. 1055-1071, 2014.

[34] Y. Liao and J. Wang, "A note on stability of impulsive differential equations," Boundary Value Problems, vol. 2014, article 67, 2014.

[35] V. Lupulescu and A. Zada, "Linear impulsive dynamic systems on time scales," Electronic Journal of Qualitative Theory of Differential Equations, vol. 11, pp. 1-30, 2010.

[36] A. M. Samoilenko and N. A. Perestyuk, "Stability of solutions of differential equations with impulse effect," Differential Equations, vol. 13, pp. 1981-1992, 1977.

[37] I. A. Rus, "Gronwall lemmas: ten open problems," Scientiae Mathematicae Japonicae, vol. 70, no. 2, pp. 221-228, 2009. 


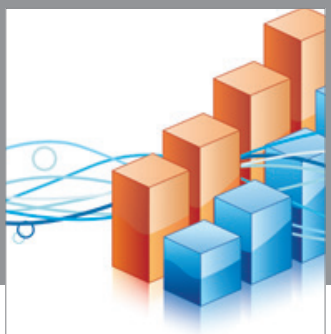

Advances in

Operations Research

vatem alat4

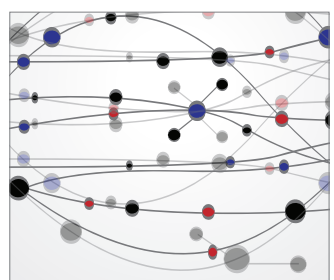

\section{The Scientific} World Journal
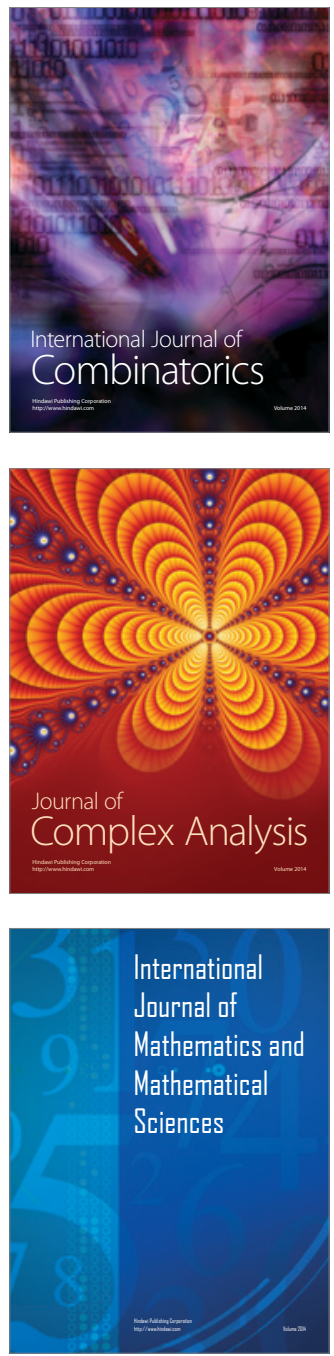
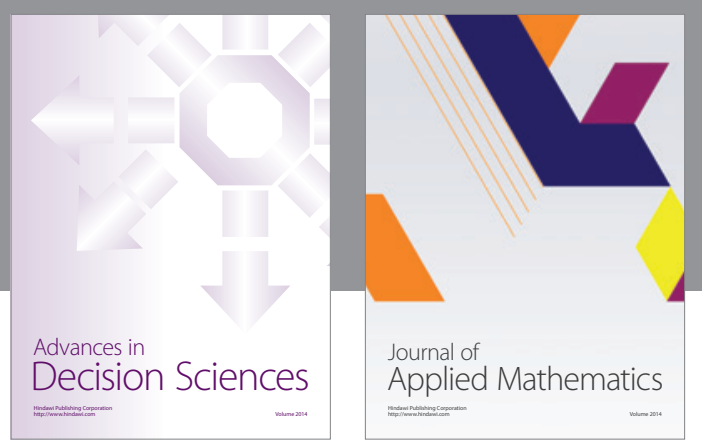

Algebra

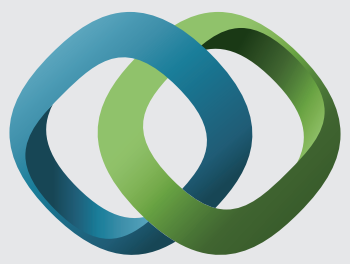

\section{Hindawi}

Submit your manuscripts at

http://www.hindawi.com
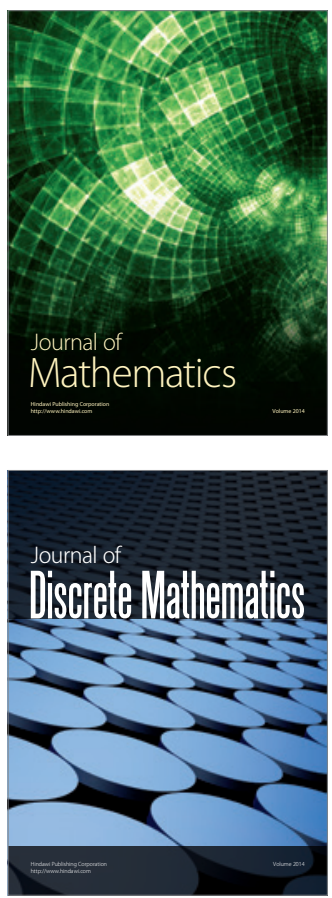

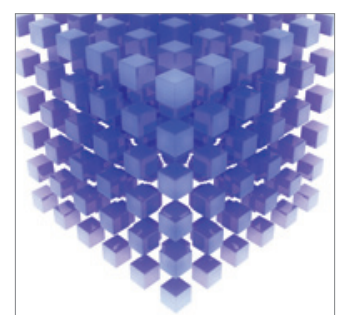

Mathematical Problems in Engineering
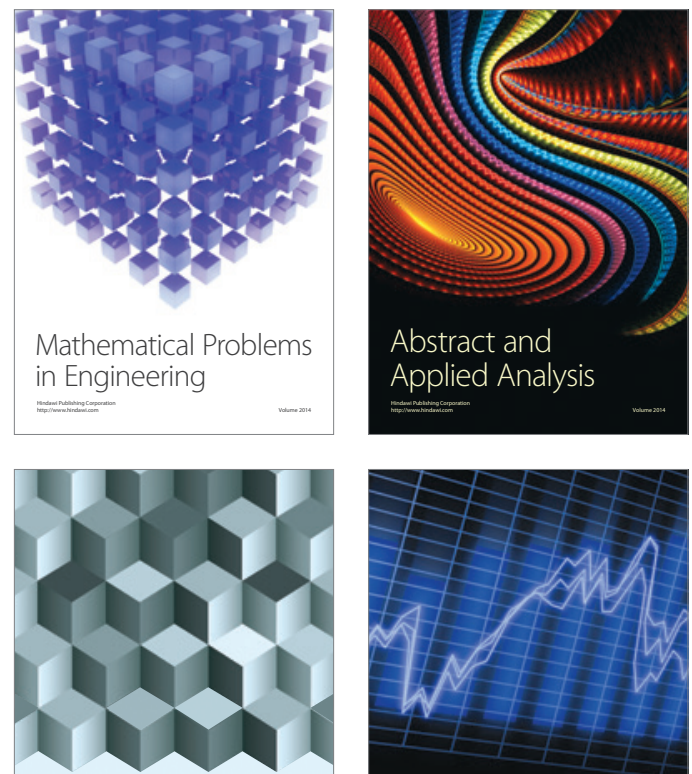

Journal of

Function Spaces

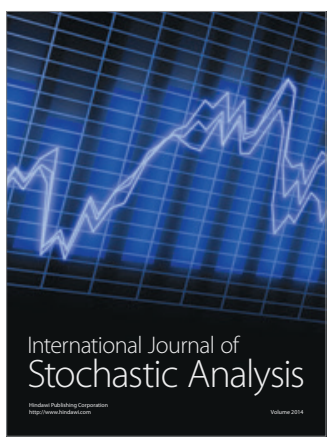

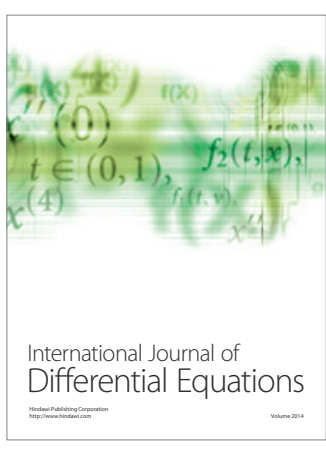
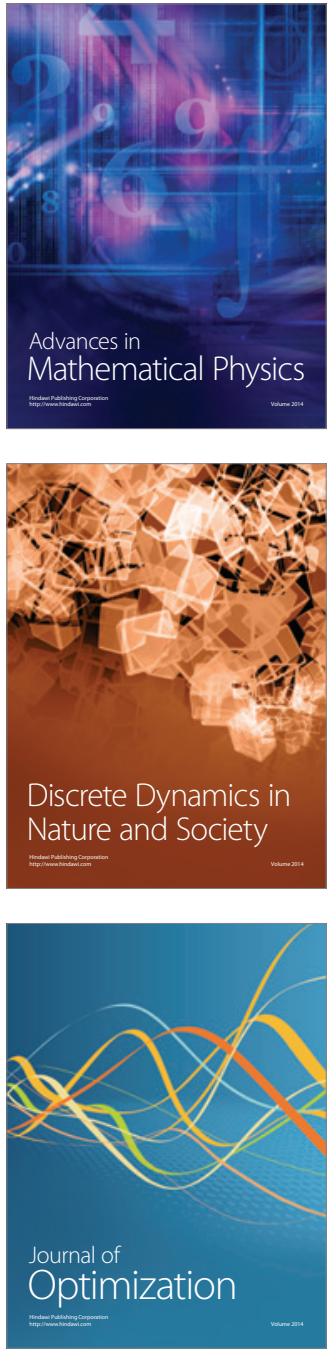